\title{
Correction to: Outcomes After Distal Pancreatectomy with Celiac Axis Resection for Pancreatic Cancer: A Pan-European Retrospective Cohort Study
}

Sjors Klompmaker, MD ${ }^{1}$ (D) Jony van Hilst, MD, Msc ${ }^{1}$, Sarah L. Gerritsen, BSc ${ }^{1}$, Mustapha Adham, MD $^{2}$, M. Teresa Albiol Quer, $\mathrm{MD}^{3}$, Claudio Bassi, $\mathrm{MD}^{4}$, Frederik Berrevoet, $\mathrm{MD}^{5}$, Ugo Boggi, $\mathrm{MD}^{6}$, Olivier R. Busch, $\mathrm{MD}, \mathrm{PhD}^{1}$, Manuela Cesaretti, $\mathrm{MD}^{7}$, Raffaele Dalla Valle, $\mathrm{MD}^{8}$, Benjamin Darnis, $\mathrm{MD}^{9}$, Matteo De Pastena, $\mathrm{MD}^{4}$, Marco Del Chiaro, $\mathrm{MD}^{10}$, Robert Grützmann, $\mathrm{MD}^{11}$, Markus K. Diener, $\mathrm{MD}^{12}$, Traian Dumitrascu, $\mathrm{MD}^{13}$, Helmut Friess, $\mathrm{MD}^{14}$, Arpad Ivanecz, $\mathrm{MD}^{15}$, Anastasios Karayiannakis, $\mathrm{MD}^{16}$, Giuseppe K. Fusai, $\mathrm{MD}^{17}$, Knut J. Labori, MD, $\mathrm{PhD}^{18}$, Carlo Lombardo, $\mathrm{MD}^{6}$, Santiago López-Ben, $\mathrm{MD}^{3}$, Jean-Yves Mabrut, $\mathrm{MD}^{9}$, Willem Niesen, $\mathrm{MD}^{12}$, Fernando Pardo, $\mathrm{MD}^{19}$, Julie Perinel, $\mathrm{MD}^{2}$, Irinel Popescu, $\mathrm{MD}^{13}$, Geert Roeyen, $\mathbf{M D}^{20}$, Alain Sauvanet, $\mathrm{MD}^{7}$, Raj Prasad, $\mathrm{MD}^{21}$, Christian Sturesson, $\mathrm{MD}^{22}$, Mickael Lesurtel, MD, PhD ${ }^{9}$, Jorg Kleeff, $\mathrm{MD}^{23}$, Roberto Salvia, $\mathrm{MD}^{4}$, Marc G. Besselink, MD, Msc, PhD $^{1}$, and the E-AHPBA DP-CAR study group

${ }^{1}$ Department of Surgery, Cancer Center Amsterdam, Academic Medical Center, Amsterdam, the Netherlands; ${ }^{2}$ Department of Digestive Surgery, E. Herriot Hospital, HCL, UCBL1, Lyon, France; ${ }^{3}$ Department of Surgery, Hospital Universitari de Girona Dr. Josep Trueta, Girona, Spain; ${ }^{4}$ Department of Surgery, University of Verona, Verona, Italy; ${ }^{5}$ Department of General and HPB Surgery, Ghent University Hospital, Ghent, Belgium; ${ }^{6}$ Division of General and Transplant Surgery, University of Pisa, Pisa, Italy; ${ }^{7}$ Department of HPB Surgery, Hôpital Beaujon, Clichy Cedex, France; ${ }^{8}$ Hepato-PancreatoBiliary Unit, Parma University Hospital, Parma, Italy; ${ }^{9}$ Department of Surgery and Liver Transplantation, Croix-Rousse University Hospital, Hospices Civils de Lyon, University of Lyon I, Lyon, France; ${ }^{10}$ Department of Clinical Science, Intervention and Technology, Karolinska University Hospital, Stockholm, Sweden; ${ }^{11}$ Department of Surgery, University Hospital Erlangen, Erlangen, Germany; ${ }^{12}$ Department of General, Visceral and Transplantation Surgery, Heidelberg University, Heidelberg, Germany; ${ }^{13}$ Center of General Surgery and Liver Transplant, Fundeni Clinical Institute, Bucharest, Romania; ${ }^{14}$ Department of Surgery, Klinikum rechts der Isar, School of Medicine, Technical University of Munich, Munich, Germany; ${ }^{15}$ Department of Abdominal and General Surgery, University Medical Centre Maribor, Maribor, Slovenia; ${ }^{16}$ Second Department of Surgery, Democritus University of Thrace, Alexandroupolis, Greece; ${ }^{17} \mathrm{HPB}$ Surgery and Liver Transplantation Unit, Royal Free Hospital, London, UK; ${ }^{18}$ Department of Hepato-Pancreato-Biliary Surgery, Oslo University Hospital, Oslo, Norway; ${ }^{19}$ Department of HPB and Transplant Surgery, Clínica Universidad de Navarra, Pamplona, Spain; ${ }^{20}$ Department of Hepatobiliary, Endocrine and Transplantation Surgery, Antwerp University Hospital, Antwerp, Belgium; ${ }^{21}$ Department of HPB and Transplant Services, National Health Service, Leeds, UK; ${ }^{22}$ Department of Surgery, Skåne University Hospital, Lund, Sweden; ${ }^{23}$ Department of Visceral, Vascular and Endocrine Surgery, MartinLuther-University Halle-Wittenberg, Halle, Germany

CORRECTION TO: ANN SURG ONCOL HTTPS://DOI.ORG/10.1245/S10434-018-6391-Z

The original article can be found online at https://doi.org/10.1245/ s10434-018-6391-z.

(C) Society of Surgical Oncology 2018

Published Online: 20 March 2018

M. G. Besselink, MD, Msc, PhD

e-mail: m.g.besselink@amc.nl
In the original article, the institutional author the E-AHPBA DP-CAR study group was misspelled. It is correct as reflected here. The original article has also been corrected. 